\title{
NOTE
}

\section{Arthrobacter rhombi sp. nov., isolated from Greenland halibut (Reinhardtius hippoglossoides)}

\author{
Carlos R. Osorio, ${ }^{1}$ Juan L. Barja, ${ }^{1}$ Roger A. Hutson ${ }^{2}$ \\ and Matthew D. Collins ${ }^{2}$ \\ Author for correspondence: Matthew D. Collins. Tel: +44 1189 357226. Fax: +441189357222. \\ e-mail: david.collins@bbsrc.ac.uk
}

\footnotetext{
1 Departamento de Microbiologia y Parasitologia, Universidad de Santiago de Compostela, Santiago de Compostela 15706, Spain

2 Department of Food Science and Technology, University of Reading, Reading RG6 6AP, UK
}

\author{
Two strains of a hitherto undescribed Gram-positive coryneform bacterium \\ isolated from Greenland halibut (Reinhardtius hippoglossoides) were \\ characterized by phenotypic and molecular taxonomic methods. Comparative \\ 165 rRNA gene sequencing studies demonstrated that the unknown strains \\ constitute a new line within the genus Arthrobacter. The nearest relatives of \\ the bacterium from fish were members of the Arthrobacter nicotianael \\ Arthrobacter sulfureus group. The unknown bacterium was readily \\ distinguished from these species by phenotypic methods. Based on \\ phylogenetic and phenotypic evidence, it is proposed that the unknown \\ bacterium be classified as Arthrobacter rhombi sp. nov. The type strain of \\ Arthrobacter rhombi is CCUG $38813^{\top}$.
}

Keywords: Arthrobacter rhombi sp. nov., taxonomy, phylogeny, 16S rRNA analysis
The genus Arthrobacter comprises a group of catalasepositive, strictly aerobic, asporogenous rod-shaped bacteria which display a coryneform morphology. Species of the genus Arthrobacter invariably contain cell wall mureins based upon the dibasic amino acid L-lysine (Schleifer \& Kandler, 1972) and, phylogenetically, they are members of the Actinomycete branch of the Gram-positive bacteria (Stackebrandt et al., 1997). Amongst species of Arthrobacter, two major cell wall murein structural types are recognized, which are designated $\mathrm{A} 3 \alpha$ and $\mathrm{A} 4 \alpha$ (for murein nomenclature, see Schleifer \& Kandler, 1972). Arthrobacter globiformis, the type species of the genus, and most of the other species possess type A3 $\alpha$ in which crosslinkage of murein is by interpeptide bridges consisting of monocarboxylic L-amino acids or glycine, or both. However, a distinct cluster of organisms, viz. Arthrobacter nicotianae, Arthrobacter protophormiae and Arthrobacter uratoxydans referred to as the Arthrobacter nicotianae group, possess A $4 \alpha$ mureins in which cross-linkage is by interpeptide bridges containing a dicarboxylic amino acid (type L-Lys-Ala-Glu)

\footnotetext{
Abbreviations: BHA, brain heart infusion agar; CCUG, Culture Collection of the University of Goteborg; RDP, Ribosomal Database Project.

The GenBank accession numbers for the 16S rRNA gene sequences of strains CCUG 38812 and CCUG $38813^{\top}$ are $Y 15885$ and $Y 15884$, respectively.
}

(Stackebrandt et al., 1983). Arthrobacter sulfureus, which is phylogenetically associated with the $A$. nicotianae group of species (Stackebrandt et al., 1995; Funke et al., 1996), also contains an A $4 \alpha$ murein but of a slightly modified structure (i.e. type L-Lys-L-Glu) (Stackebrandt et al., 1983). Certain Micrococcus species (viz. Micrococcus luteus and Micrococcus lylae) and Renibacterium salmoninarum are phylogenetically intermixed with species of the genus Arthrobacter (Stackebrandt et al., 1995). Of these taxa, only M. lylae exhibits an A4 $\alpha$ murein (type L-Lys-D-Asp), and comparative 16S rRNA gene sequencing indicates this organism does not have a specific phylogenetic association with the $A$. nicotianae group or $A$. sulfureus (Stackebrandt et al., 1995; Funke et al., 1996). In this article, we report the characteristics of a hitherto unknown Arthrobacter species isolated from Greenland halibut which also contains an A4 $4 \alpha$ cell wall murein. Based on both phenotypic and phylogenetic evidence, a new species, Arthrobacter rhombi sp. nov., is described.

Two strains designated F.58.3CB.57 and F.98.3HR.69 ${ }^{\mathrm{T}}$ were recovered from organs of Greenland halibut (Reinhardtius hippoglossoides). Samples of kidney, spleen and gut were taken from a number of fish from different species including Greenland halibut, captured by deep trawl (300- 
$800 \mathrm{~m}$ ) during a fishing expedition carried by the Spanish oceanographic vessel Cornide de Saavedra. The expedition was part of a pluriannual study of the stock populations of fish in the deep waters of the Flemish Cap fishing ground (Newfoundland, NW Atlantic). The temperature of the water at the point of study was $3.5-4.0^{\circ}$ C. Strains F.58.3CB.57 and F.98.3HR.69 $9^{\mathrm{T}}$ have been deposited in the Culture Collection of the University of Göteborg (CCUG), Sweden, under accession numbers CCUG 38812 and CCUG $38813^{\mathrm{T}}$, respectively. The strains were cultured on brain heart infusion agar (BHA) supplemented with $1 \%(\mathrm{w} / \mathrm{v}) \mathrm{NaCl}$ at $25^{\circ} \mathrm{C}$. The strains were biochemically characterized by using the API CORYNE and API 50CH systems according to the manufacturer's instructions (API bioMérieux). The cell wall murein structure of strain CCUG $38813^{\mathrm{T}}$ was determined by the method of Schleifer \& Kandler (1972) except that ascending TLC on cellulose sheets (Merck) was used. The $\mathrm{G}+\mathrm{C}$ content of DNA of strain CCUG $38813^{\mathrm{T}}$ was determined by thermal denaturation ( $T_{\mathrm{m}}$ method; Garvie, 1978). The $16 \mathrm{~S}$ rRNA genes of the isolates were amplified by PCR and directly sequenced using a Taq DyeDeoxy Terminator Cycle Sequencing kit (Applied Biosystems) and an automatic DNA sequencer (model 373A; Applied Biosystems). The closest known relatives of the new isolates were determined by performing database searches. These sequences and those of other known related strains were retrieved from GenBank or Ribosomal Database Project (RDP) Libraries and aligned with the newly determined sequences using the program PILEUP (Devereux et al., 1984). The resulting multiple sequence alignment was corrected manually and a distance matrix was calculated using the program PRETTY from DNADIST (using the Kimura-2 correction parameter) (Felsenstein, 1989). A phylogenetic tree was constructed according to the neighbour-joining method with the program NEIGHBOR (Felsenstein, 1989). The stability of the groupings was estimated by bootstrap analysis (200 replications) using the programs DNABOOT, DNADIST, NEIGHBOR and CONSENSE (Felsenstein, 1989). In addition, parsimony analysis (Felsenstein, 1989) was performed on the same data set. The 16S rRNA gene sequences of both strains CCUG 38812 and CCUG $38813^{\mathrm{T}}$ have been deposited in GenBank under accession numbers Y15885 and Y15884, respectively.

The two isolates were short rods or ovoid in shape and formed single cells. On BHA, strain CCUG 38812 had a whitish-yellow pigmentation, whereas strain CCUG $38813^{\text {T }}$ had an intense yellow pigmentation. Both strains were Gram-positive obligate aerobes. They grew in 1 and $10 \%(\mathrm{w} / \mathrm{v}) \mathrm{NaCl}$, at 4 and $30^{\circ} \mathrm{C}$. Using the API 50CH system, both isolates utilized glycerol, galactose, D-glucose, D-fructose, D-mannose, mannitol, amygdalin, arbutin, aesculin, salicin, cellobiose, maltose, lactose, melibiose, sucrose, trehalose, $\beta$ gentiobiose, D-turanose, gluconate and D-arabitol as sole carbon sources (Table 1). Both strains failed to
Table 1. Biochemical characteristics of Arthrobacter rhombi sp. nov. and its closest relatives

Strains: 1 , A. rhombi CCUG $38812,38813^{\mathrm{T}} ; 2$, A. sulfureus NCIMB $10355^{\mathrm{T}} ; 3, A$. uratoxydans DSM $20647^{\mathrm{T}} ; 4, A$. protophormiae NCIMB $12765^{\mathrm{T}} ; 5$, A. nicotianae DSM $20123^{\mathrm{T}}$.

\begin{tabular}{|c|c|c|c|c|c|}
\hline Characteristic & 1 & 2 & 3 & 4 & 5 \\
\hline \multicolumn{6}{|l|}{ Activities:* } \\
\hline Nitrate reduction & - & - & + & + & + \\
\hline Pyrazinamidase & - & + & + & + & + \\
\hline$\beta$-Galactosidase & + & - & - & - & - \\
\hline Urease & - & + & + & - & - \\
\hline \multicolumn{6}{|l|}{ Assimilation of $: \dagger$} \\
\hline Amygdalin & + & - & - & - & + \\
\hline Arbutin & + & - & - & - & + \\
\hline Cellobiose & + & - & - & + & + \\
\hline D-Arabitol & + & + & - & - & + \\
\hline D-Mannose & + & - & - & - & - \\
\hline D-Turanose & + & - & - & - & - \\
\hline D-Xylose & - & - & - & - & + \\
\hline Galactose & + & - & - & $-\ddagger$ & + \\
\hline Glycerol & + & - & $+\S$ & + & + \\
\hline Inositol & - & + & - & - & - \\
\hline L-Arabinose & - & - & - & - & + \\
\hline Maltose & + & + & - & + & + \\
\hline Mannitol & + & + & - & - & - \\
\hline Melibiose & + & - & - & - & - \\
\hline Rhamnose & $\mathrm{v}$ & - & $-\div$ & - & - \\
\hline Ribose & - & - & $+\S$ & - & + \\
\hline Salicin & + & - & - & - & + \\
\hline Starch & - & - & - & - & + \\
\hline Sucrose & + & - & - & - & - \\
\hline Trehalose & + & - & - & - & - \\
\hline Xylitol & - & + & - & - & - \\
\hline$\beta$-Gentiobiose & + & - & - & - & + \\
\hline$N$-Acetylglucosamine & - & - & + & - & - \\
\hline 5-Ketogluconate & - & + & - & + & - \\
\hline
\end{tabular}

* API CORYNE system.

† Carbohydrate assimilation reactions: API 50CH and AUX Medium, incubated at $25^{\circ} \mathrm{C}$ (Funke \& Carlotti, 1994); +, positive; - , negative; $v$, variable.

$¥$ Positive in the study of Hou et al. (1998).

$\S$ Negative in the study of Hou et al. (1998).

assimilate erythritol, D-arabinose, L-arabinose, ribose, $\mathrm{D}$-xylose, adonitol, methyl $\beta$-xyloside, L-sorbose, dulcitol, sorbitol, methyl $\alpha$-D-mannoside, methyl $\alpha$-Dglucoside, inositol, $N$-acetylglucosamine, inulin, melezitose, D-raffinose, starch, glycogen, xylitol, D-lyxose, D-tagatose, D-fucose, L-fucose, L-arabitol, 2-ketogluconate and 5-ketogluconate as sole carbon sources. Rhamnose was utilized by strain CCUG 38812 but not by CCUG $38813^{\mathrm{T}}$. Using the API CORYNE system, both isolates showed $\beta$-galactosidase activity; no activity for pyrazinamidase or urease was detected. Neither strain reduced nitrate. An examination of the 


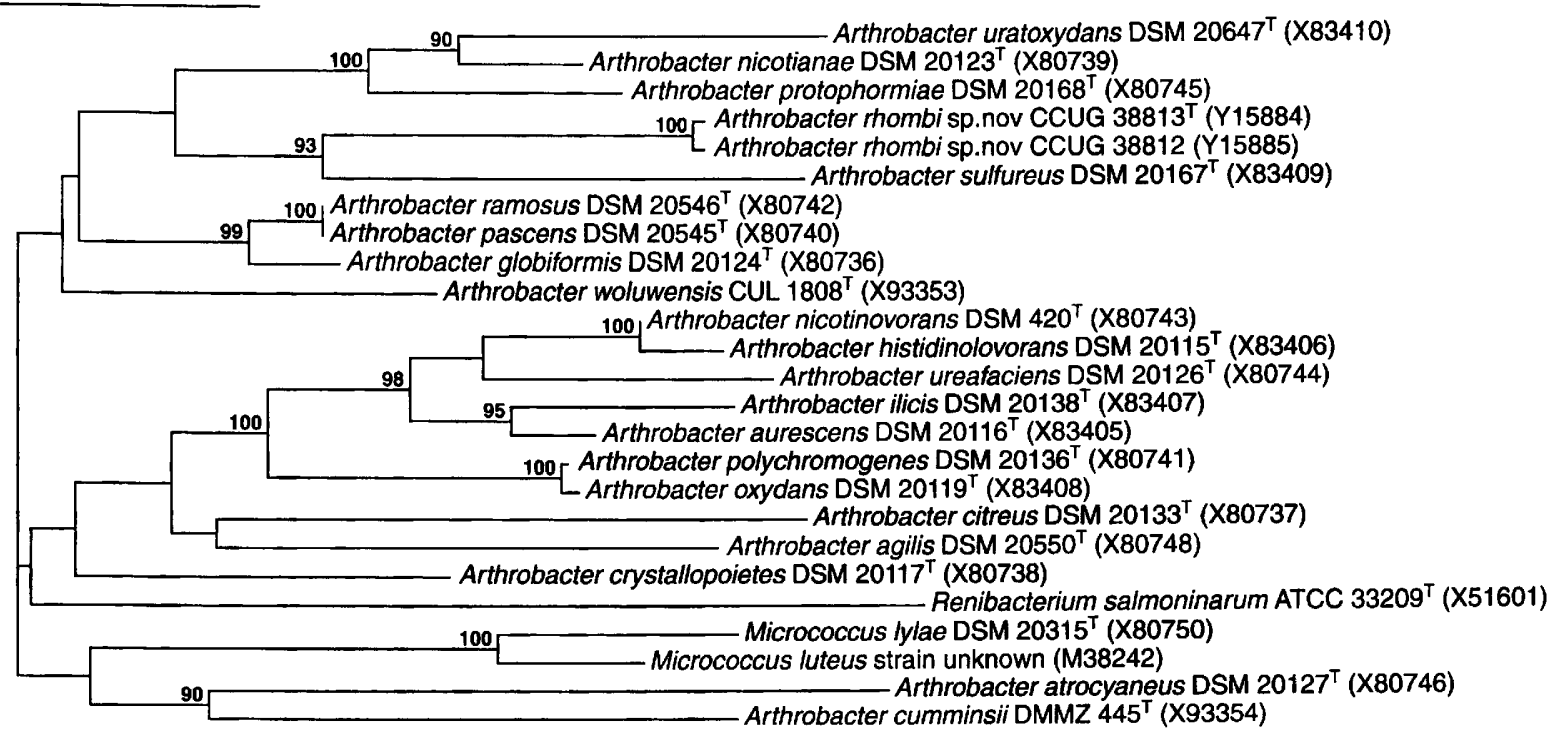

Fig. 1. Unrooted tree showing the phylogenetic relationships of Arthrobacter rhombi sp. nov. within the genus Arthrobacter. The tree constructed using the neighbour-joining method was based on a comparison of approx. 1320 nucleotides. Bootstrap values, expressed as a percentage of 200 replications, are given at branching points. Bar, $1 \%$ sequence divergence. With the exception of $A$. rhombi CCUG 38812, all other strains are type strains; accession numbers are given in parentheses.

cell wall of strain CCUG $38813^{\mathrm{T}}$ revealed the presence of an A4 $\alpha$ murein (type L-Lys-L-Ala-D-Glu). Within the coryneform group of bacteria, this murein type is found within the $A$. nicotianae group (viz. $A$. nicotianae, A protophormiae, A. uratoxydans, Arthrobacter creatinolyticus) (Schleifer \& Kandler, 1972; Stackebrandt et al., 1983; Hou et al., 1998). A. sulfureus also contains an A4 $\alpha$ murein but this is of the L-Lys-L-Glu type (Schleifer \& Kandler, 1972). To investigate the phylogenetic affinity between the two isolates, and their relationship with other coryneform taxa, comparative 16S rRNA gene sequence analyses were performed. The almost complete gene sequence ( $>1400$ nucleotides) of the two strains was determined and pairwise analysis revealed $99.9 \%$ sequence similarity (corresponding to a single base difference) thereby showing their high phylogenetic relatedness. Sequence searches of GenBank and RDP Libraries revealed that the unknown bacterium was phylogenetically most closely associated with members of the genus Arthrobacter (data not shown). Highest sequence relatedness values were shown to $A$. sulfureus ( $96.7 \%$ similarity), A nicotianae (96.6\% similarity), $A$. protophormiae ( $95.6 \%$ similarity) and $A$. uratoxydans $(95.8 \%$ similarity). A tree constructed by the neighbour-joining method depicting phylogenetic affinities of the unknown bacterium is shown in Fig. 1. From the branching pattern of the tree, the nearest relative of the unknown bacterium was $A$. sulfureus. The clustering together of these organisms occurred in $93 \%$ of 200 tree replications. The next nearest relatives of the aforementioned taxa corresponded to $A$. nicotianae, A. uratoxydans and $A$. protophormiae.
The yellow-pigmented coryneform isolates from halibut phenotypically resembled the genus Arthrobacter. In particular, the presence of an A $4 \alpha$ type L-Lys-L-Ala$D$-Glu murein indicated that the unknown isolates were members of the A. nicotianae group of organisms. The results of 16S rRNA gene sequencing confirmed the placement of the fish bacterium within the genus Arthrobacter but showed $A$. sulfureus to be its nearest relative (Fig. 1). The association between the unknown bacterium and $A$. sulfureus was statistically highly significant. The $A$. nicotianae group was, however, the next nearest relative of the unknown bacterium. Sequence divergence values between the fish bacterium and $A$. sulfureus and the $A$. nicotianae group were $>3 \%$ and unequivocally demonstrated its separate species status. In this context, it is pertinent to note that the levels of sequence divergence shown between the fish bacterium and the aforementioned taxa are significantly greater than those shown between several genomically distinct Arthrobacter species. In addition to differing from $A$. sulfureus in murein composition, the unknown bacterium was readily differentiated from this species in assimilating a larger number of carbohydrates and by its positive reaction with $\beta$-galactosidase and negative reactions with pyrazinamidase and urease. Similarly, the bacterium from halibut was readily distinguished from species of the $A$. nicotianae group by its distinct carbohydrate assimilation reactions and enzymic profile (see Table 1). Recently, a new member of the $A$. nicotianae group, $A$. creatinolyticus (isolated from human urine) was described (Hou et al., 1998). The closest relative of the latter species is A. protophormiae (Hou et al., 1998). 
16S rRNA pairwise analysis between the unknown bacterium (accession no. Y15884) from fish and $A$. creatinolyticus (accession no. D88212) clearly showed that these taxa are phylogenetically quite separate species (approx. 10\% sequence divergence). In view of the distinct biochemical features and separate $16 \mathrm{~S}$ rRNA subline formed by the unknown Arthrobacter from fish, we propose that it be designated a new species, Arthrobacter rhombi sp. nov.

\section{Description of Arthrobacter rhombi sp. nov.}

Arthrobacter rhombi (rhom'bi. L. masc. N. rhombus flatfish; rhombi of flatfish).

Cells are Gram-positive, short rods and cocci. They are non-spore-forming and non-motile. On BHA, smooth convex colonies which are yellowish or whitish in colour and with a diameter of approx. $1 \mathrm{~mm}$ are formed after $48 \mathrm{~h}$. Growth occurs in $1 \%(\mathrm{w} / \mathrm{v})$ and $10 \%(\mathrm{w} / \mathrm{v}) \mathrm{NaCl}$ and at 4 and $30^{\circ} \mathrm{C}$. They are strictly aerobic and catalase- and oxidase-positive. By using the API CORYNE system, positive reactions for $\beta$-galactosidase and esculinase are observed. Negative reactions are obtained for nitrate reductase, pyrazinamidase, pyrrolidonyl arylamidase, urease, $\beta$-glucuronidase, $N$-acetyl- $\beta$-glucosaminidase and gelatinase. Using the API 50CH system, the following substrates are used as sole carbon sources: glycerol, galactose, D-glucose, D-fructose, D-mannose, mannitol, amygdalin, arbutin, aesculin, salicin, cellobiose, maltose, lactose, melibiose, sucrose, trehalose, $\beta$-gentiobiose, D-turanose, gluconate and $\mathrm{D}$-arabitol. Erythritol, D-arabinose, L-arabinose, ribose, D-xylose, adonitol, methyl $\beta$-xyloside, L-sorbose, dulcitol, sorbitol, methyl $\alpha$-D-mannoside, methyl $\alpha$-D-glucoside, inositol, $N$-acetyl- $\beta$-glucosamine, inulin, melezitose, D-raffinose, starch, glycogen, xylitol, D-lyxose, D-tagatose, D-fucose, L-fucose, L-arabitol, 2-ketogluconate and 5-ketogluconate are not utilized. The cell wall murein type is A4 $\alpha$ (L-Lys-L-Ala-D-Glu). The $\mathrm{G}+\mathrm{C}$ content of DNA is $61 \mathrm{~mol} \%\left(T_{\mathrm{m}}\right.$ method). Isolated from organs of Greenland halibut (Reinhardtius hippoglossoides) in the deep waters of the Flemish Cap fishing ground (Newfoundland, NW Atlantic). The type strain, CCUG $38813^{\mathrm{T}}$, was isolated from the spleen of Reinhardtius hippoglossoides.

\section{Acknowledgements}

We are grateful to Professor Hans Trüper for coining the species epithet. The authors thank Dr Antonio Vázquez from the Instituto de Investigaciones Marinas (CSIC), Vigo, Spain, for allowing us to participate in the Flemish Cap-94 research campaign as well as the crew of the $\mathrm{B} / \mathrm{O}$ Cornide de Saavedra.

\section{References}

Devereux, J., Haeberli, P. \& Smithies, O. (1984). A comprehensive set of sequence analysis programs for the VAX. Nucleic Acids Res 12, 387-395.

Felsenstein, J. (1989). PHYLIP - phylogeny inference package (version 3.2). Cladistics 5, 164-166.

Funke, G. \& Carlotti, A. (1994). Differentiation of Brevibacterium spp. encountered in clinical specimens. J Clin Microbiol 32, 1729-1732.

Funke, G., Hutson, R. A., Bernard, K. A., Pfyffer, G. E., Wauters, G. \& Collins, M. D. (1996). Isolation of Arthrobacter spp. from clinical specimens and description of Arthrobacter cumminsii sp. nov. and Arthrobacter woluwensis sp. nov. J Clin Microbiol 34, 2356-2363.

Garvie, E. I. (1978). Streptococcus raffinolactis (Orla-Jensen and Hensen); a group $\mathrm{N}$ streptococcus found in raw milk. Int $J$ Syst Bacteriol 28, 190-193.

Hou, X.-G., Kawamura, Y., Sultana, F., Shu, S., Hirose, K., Goto, K. \& Ezaki, T. (1998). Description of Arthrobacter creatinolyticus sp. nov., isolated from human urine. Int $J$ Syst Bacteriol 48, 423-429.

Schleifer, K. H. \& Kandler, O. (1972). Peptidoglycan types of bacterial cell walls and their taxonomic implications. Bacteriol Rev 36, 407-477.

Stackebrandt, E., Fowler, J. J. , Fiedler, F. \& Seiler, H. (1983). Taxonomic studies on Arthrobacter nicotianae and related taxa: description of Arthrobacter uratoxydans sp. nov. and Arthrobacter sulfureus sp. nov. and reclassification of Brevibacterium protophormiae as Arthrobacter protophormiae comb. nov. Syst Appl Microbiol 4, 470-486.

Stackebrandt, E., Koch, C., Gvozdiak, O. \& Schumann, P. (1995). Taxonomic dissection of the genus Micrococcus: Kocuria gen. nov., Nesterenkonia gen. nov., Kytococcus gen. nov., Dermacoccus gen. nov., and Micrococcus Cohn 1872 gen. emend. Int J Syst Bacteriol 45, 682-692.

Stackebrandt, E., Rainey, F. A. \& Ward-Rainey, N. (1997). Proposal for a new hierarchic classification system, Actinobacteria classis nov. Int J Syst Bacteriol 47, 479-491. 